\title{
PREVALENCE OF METABOLIC SYNDROME AMONG FORMER ATHLETES
}

\section{ZAYED M ALTOWERQI ${ }^{1}$, ZAINAL ABIDIN BIN ZAINUDDIN ${ }^{2} \&$ HESHAM SAYED AHMED $^{3}$}

${ }^{1,3}$ Faculty of Education, Physical Education Department, Umm Al-Qura University, Makkah, Saudi Arabia

${ }^{1,2}$ Faculty of Social Sciences and Humanities, School of Education, University Technology Malaysia, Johor Bahru, Malaysia

\begin{tabular}{|l|}
\hline ABSTRACT \\
The purpose of this study is to determine the prevalence of metabolic syndrome (MS) in former athletes the Kingdom of \\
Saudi Arabia. Seventy-five (75) retired athletes, aged between 26 and 60 years old, participated in this study. Height, \\
weight, waist circumference (WC), blood pressure, and blood samples were collected by the researcher. The study findings \\
indicated that $52 \%$ of former athletes have MS. The findings of this study showed that $26.7 \%$ of former athletes have high \\
WC $\geq 102 \mathrm{~cm})$. Moreover, $66.7 \%$ of former athletes have high fasting blood glucose $\geq 100 \mathrm{mg} / \mathrm{dl})$. The results also \\
indicated that $48 \%$ of former athletes have blood pressure > $130 / 85 \mathrm{mmHg}$ In addition, $22.7 \%$ of former athletes have \\
high triglycerides $\geq 150 \mathrm{mg} / \mathrm{dl})$, and $93.3 \%$ have low high-density lipoprotein cholesterol (<40 mg/dl). \\
KEYWORDS: Former Athletes; Metabolic Syndrome; Prevalence; WC; Diabetes; HDL; Triglycerides
\end{tabular}

Received: Jun 06, 2020; Accepted: Jun 26, 2020; Published: Aug 07, 2020; Paper Id.: IJMPERDJUN2020674

\section{INTRODUCTION}

The prevalence of metabolic syndrome (MS) is an emerging health problem and has increased globally (Altowerqi, Zainuddin, Hashim, \& Sayyd, 2020). It is a combination of visceral obesity, high blood glucose, high blood pressure (BP),and abnormal lipid profile, which can predispose an individual to increased risk for cardiovascular diseases (CV) and diabetes (T2D) (Altowerqi, Zainuddin, Hashim, \& Sayyd, 2020; Emami et al., 2018). It has been reported that MS may increase two fold the risk of CV and three to five fold the risk of T2D compared to people without MS (Altowerqi, Zainuddin, Hashim, \& Sayyd, 2020; Kaur, 2014). There are several multifactorial underlying causes of MS, but genetic predisposition, obesity, low level of physical activity, and sedentary lifestyle are believed to be major underlying factors (Kaur, 2014).

The prevalence of non-communicable disease is increasing rapidly. According to the World Health Organisation (WHO), by 2020 it is predicted that non-communicable disease will be responsible for approximately 80 percent of the world burden of disease, causing 7 out of every 10 deaths in developing countries, around $50 \%$ of them early deaths under 70 years old(Islam et al., 2014). Several studies have reported a high prevalence of MS in former athletes, and it is increasing with the adoption of a sedentary lifestyle among former athletes after retirement(Altowerqi, Abidin, Sayyd, Alkuhaili, \& Alsayegh, 2020). The prevalence of MS also differs by gender, race, and ethnicity, which might affect the morbidity and mortality of individuals (Kaur, 2014).

Most studies that have highlighted the risk factors have been conducted in America or Europe(Batista \& Soares, 2013; Laine et al., 2016; Panayiotoglou et al., 2017). There are no similar studies in the Kingdom of Saudi Arabia (KSA). Thus, this study was carried out in the KSA to determine the prevalence of MS and its components factors. 


\section{METHODS}

To achieve the aim of the study, an online consent form was administered to former athletes. The link to the consent was sent to the Saudi Athletics Federation to ask them to send a request to former athletes to participate in this study. This study is limited to Saudi former athletes. Data were collected over a period of three months from January to March 2020. A total of 75 individuals agreed to participate. The research participants were former male athletes who had previously played in national and international competitions. The inclusion criterion was an age range from 20 to 60 years. Obtained data were recorded on a data collection sheet developed by the researcher. The data sheet was designed to collect demographic characteristics of the former athletes, such as age, weight, height, body mass index (BMI), waist circumference (WC), results of lipid profile, BP, and fasting blood glucose level.

Anthropometric measurements, including weight, height, and WC, were obtained. Height was measured without footwear on using a measuring high rod with platform stadiometer to an accuracy of $0.1 \mathrm{~cm}$. Body weight and body composition were determined at the same time by a bio-impedance body composition device (Omron BF511), with body weight to an accuracy of $0.1 \mathrm{~kg}$. WC was measured midway between the anterior superior iliac spine and lower edge of the rib cage in a relaxed standing posture by using meter health tape(Laine et al., 2016). For the comparisons between our groups and data from the WHO, overweight was defined as a BMI 25-29.9, and obesity was defined as a BMI $\geq 30$ $\mathrm{kg} / \mathrm{m}^{2}$ (Altowerqi, Zainuddin, Hashim, \& Almarwaey, 2020).

BP was measured using a standardised BP protocol based on the guidelines provided by the Joint National Committee on Detection, Evaluation, and Treatment of High Blood Pressure (2004)(The U.S. Department of Health and Human Services. The National Heart, Lung, 2004). BP was measured using a validated digital automatic BP monitor (Omron Healthcare, model HEM-7322, Vietnam). After 5 minutes of rest, the researcher measured BP from the participant's left arm while he was sitting in a relaxed position. BP was assessed twice, and in between the assessments, there was at least a one-minute gap. The mean of two BP values was recorded.

For laboratory analysis and all biochemical measurements, early in the morning high-density lipoprotein cholesterol (HDL), triglycerides (TG), and fasting blood glucose were taken by the researcher after an overnight fast of 1012 hours through capillary finger stick. The LipiDiag 4 in 1 optics blood lipid analyser (total cholesterol (TC), HDL, and TG cholesterol) and the Benecheck 3 in 1 (cholesterol and uric acid and glucose) meter household portable analyser (model no.BK6-12M\&1. Taiwan) were used to analyse cholesterol and glucose. The meters were set as instructed using the code numbers on the test strip bottle. The test was performed using blood from the finger of the participants on the spot. Through the measurement, a test strip was inserted to turn on the meter. The test strip was lined up with the edge of a blood drop from the participants to allow the blood drop to be drawn into the narrow channel of the test strip. Cholesterol, blood glucose, and uric acid level displayed were then recorded. The blood sample was obtained in accordance with the WHO guidelines on drawing blood (WHO, 2010)(World Health Organization, n.d.).

We defined MS using the Third Report of the National Cholesterol Education Program (NCEP) Expert's Panel on Detection, Evaluation, and Treatment of High Blood Cholesterol in Adults (Adult Treatment Panel III). The current ATP III criteria describe MS when there are any three of the following characteristics: 'visceral obesity, defined as a waist circumference $>102 \mathrm{~cm}$ in male and $>88 \mathrm{~cm}$ in female; serum triglycerides, $\geq 150 \mathrm{mg} / \mathrm{dL}$; serum HDL cholesterol, $<40$ $\mathrm{mg} / \mathrm{dL}$ in male and $<50 \mathrm{mg} / \mathrm{dL}$ in female; blood pressure (BP), $\geq 130 / 85 \mathrm{~mm} \mathrm{Hg}$; and fasting blood glucose, $\geq 100 \mathrm{mg} / \mathrm{dL}$ ' (Altowerqi, Zainuddin, Hashim, \& Sayyd, 2020). 


\section{STATISTICAL ANALYSIS}

Continuous data are reported as mean \pm standard deviations, and categorical variables as frequencies and number (percentage). Comparative analysis involving two variables was performed using an independent sample t-test, while analyses involving more than two variables used tests with one-way ANOVA. Statistical analysis was performed using SPSS software version 23 . The p-values $<0.05$ were considered to be statistically significant.

\section{RESULTS}

Data were obtained from health and physiological measurements and questionnaire responses. The total number of participants in this study was 75 . All were former athletes from the KSA.

Table 1 show the demographic and lifestyle variables, and Figure 1 shows the prevalence of MS. As can be seen in Table 1, the mean weight and height of the former athletes were $175.43 \mathrm{~cm}(\mathrm{SD}=8.02)$ and $86.64 \mathrm{~kg}(\mathrm{SD}=16.35)$, respectively. The mean age of the former athletes was 41.97 years old $(\mathrm{SD}=7.54)$ and ranged from 24 to 59 years old. With regard to smoking status, $36.00 \%$ of former athletes and $15.38 \%$ of non-athletes were smokers. In addition, $73.33 \%$ of former athletes and $73.08 \%$ of non-athletes were reported to eat fast food.

Table 1: Anthropometric and Lifestyle Variables of the Sample (Expressed as mean \pm SD or n, with their Corresponding Percentages)

\begin{tabular}{|l|c|}
\hline & Former Athletes (N = 75) \\
\hline Age $($ mean \pm SD) & $41.97(7.54)$ \\
\hline Height (mean \pm SD) & $175.43(8.02)$ \\
\hline Weigh (mean \pm SD) & $86.64(16.35)$ \\
\hline BMI (mean \pm SD) & \\
Underweight & $4.00 \%$ \\
Normal weight & $17.33 \%$ \\
Overweight & $42.67 \%$ \\
Obesity & $36.00 \%$ \\
\hline Smoking status (\%) & $36.00 \%$ \\
\hline Fast food (\%) & $73.33 \%$ \\
\hline
\end{tabular}

The study findings indicated that $52 \%$ of former athletes have MS. The results also showed that $26.7 \%$ of former athletes have high WC ( $\geq 102 \mathrm{~cm}$ ). Moreover, $66.7 \%$ of former athletes have high fasting blood glucose $(\geq 100 \mathrm{mg} / \mathrm{dl}$ ). Also, the results indicated that $48 \%$ of former athletes have BP > 130/85 mmHg. In addition, $22.7 \%$ of former athletes have high TG $(\geq 150 \mathrm{mg} / \mathrm{dl})$, and $93.3 \%$ have low $\mathrm{HDL}(<40 \mathrm{mg} / \mathrm{dl})$.

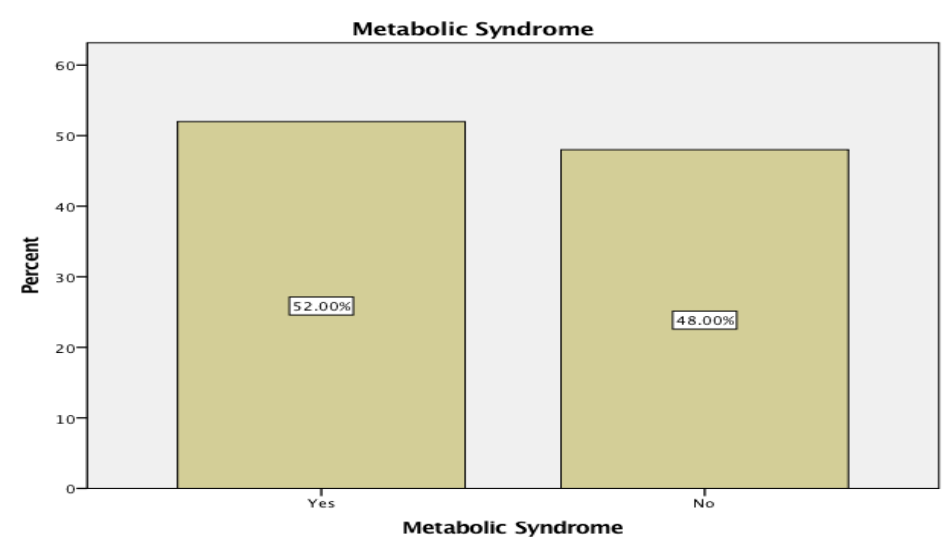

Figure 1: Prevalence of MS among Former Athletes. 


\section{DISCUSSION}

To the best of our knowledge, no study has investigated the prevalence of MS among former athletes in the KSA. Furthermore, there is a scarcity of available information regarding the burden of MS in former athletes in general. Hence, the current study was to determine the prevalence of MS and its risk factors between former athletes in the KAS.

There is a general misconception that former athletes are healthy, but $52 \%$ of the participants have MS. The most prevalent defining criterion was low HDL cholesterol (93.3\%), followed by high fasting glucose (66.7\%), with high elevated TG being the least prevalent.

Although former athletes were generally perceived as a healthier group(Batista \& Soares, 2013), 26.7\% of the former athletes had abdominal obesity,36\% were obese, and $42.67 \%$ were overweight, highlighting the importance of creating specialized programmes for weight management for former athletes. This study highlights the need to monitor the BMI status for this population, as increased BMI are associated with increased risk of developing MS. Proper intervention programmes to lower BMI and body weight should be established between former athletes, in particular for those who have high BMI, to decrease their risk of MS or its risk factors.

The prevalence of MS identified in this study is in line with similar studies of Laine et al. (51\%), Batista and Soares (50\%), and Emami et al. (53.3\%), which reported that the prevalence of MS is high. However, it was higher than the findings by Panayiotoglou et al. (25\%) (Batista \& Soares, 2013; Laine et al., 2016; Panayiotoglou et al., 2017). This can be a result of differences in lifestyle selections and eating behaviours, as the majority of the research were carried out in Europe and America. Many factors can justify the high prevalence of MS among retired athletes, including environmental factors, such as the weather conditions; fast food consumption; and inappropriate lifestyle behaviours, such as a low level of physical activity, which contributes to obesity that triggers high BP, high blood glucose, high serum cholesterol, and low HDL.

The present study has some limitations, including the small sample size and the time limit due to the COVID-19 outbreak. However, future studies can be conducted on a larger sample size and may include both former athletes and nonathletes to look at the effect of previous participation in sport on the prevalence of MS and its risk factors.

\section{CONCLUSIONS}

This is one of the few researches on MS and its risk factors in former athletes in Asia and the first in the KSA. It was found that MS prevalence is high among former athletes. Low HDL, high fasting blood glucose, and high BP are the most common individual components. Educational initiatives on the importance of regular physical activity and dietary changes in terms of selection and behaviours are key in improving the HDL, blood glucose, BP, and TG in former athletes. Health screening measures are significant in identifying former athletes who are at risk. Further research should be conducted on former athletes to aid in the development of a thorough intervention policy and health screening for former athletes.

\section{ETHICAL APPROVAL}

This study was approved by a panel of experts who were considered as an ethics committee for the school of education at University Technology Malaysia (UTM). 


\section{ACKNOWLEDGMENTS}

The authors would like to thank the Saudi Athletic Federation for its support during this study. The authors also would like to appreciate all the participants who took part in this study.

\section{COMPETING INTERESTS}

The authors declare that they have no competing interests.

\section{FUNDING}

No funding was obtained for this study.

\section{REFERENCES}

1. Altowerqi, Z. M., Abidin, Z., Sayyd, S. M., Alkuhaili, W. A., \& Alsayegh, M. A. (2020). Dietary habits among former athletes in Saudi Arabia. Indian Journal of Public Health Research \& Development, 11(03), 1069-1074.

2. Altowerqi, Z. M., Zainuddin, Z. A. Bin, Hashim, A. H. B. M., \& Almarwaey, A. O. (2020). Are Former Athletes Protected Against Obesity after Retirement? Indian Journal of Public Health Research \& Development, 11(02), 1995-2000.

3. Altowerqi, Z. M., Zainuddin, Z. A. bin, Hashim, A. H. B. M., \& Sayyd, S. M. (2020). Metabolic syndrome and its components in former athletes: A review. International Journal of Psychosocial Rehabilitation, 24(06), 8819-8835.

4. Animesh, H., C. B. Kalyan, and M. Swatik. "Effect of aerobic exercise training on body composition and heart rate recovery in overweight and obese sedentary Indian women." Journal of Medicine and Pharmaceutical Sciences 5.1 (2015): 1-6.

5. Batista, C., \& Soares, J. M. (2013). Are former elite athletes more protected against metabolic syndrome? Journal of Cardiology, 61(6), 440-445. https://doi.org/10.1016/j.jjcc.2013.01.011

6. Cáceres-Medina, Juliana, Carolina Bassol-Cámara, and Eric. Murillo-Rodríguez. "Endogenous levels of adenosine in obese patients before and after hypocaloric diet treatment." International Journal of Medicine and Pharmaceutical Sciences 5.3 (2015): 1-8.

7. Emami, M., Behforouz, A., Jarahi, L., Zarifian, A., Rashidlamir, A., Rashed, M. M., ... Ghaneifar, Z. (2018). The Risk of Developing Obesity, Insulin Resistance, and Metabolic Syndrome in Former Power - sports Athletes - Does Sports Career Termination Increase the Risk. Indian Journal of Endocrinology and Metabolism, 515-519. https://doi.org/10.4103/ijem.IJEM

8. Islam, S. M. S., Purnat, T. D., Phuong, N. T. A., Mwingira, U., Schacht, K., \& Fröschl, G. (2014). Non Communicable Diseases (NCDs) in developing countries: A symposium report. Globalization and Health, 10(1). https://doi.org/10.1186/s12992-014-0081-9

9. Kaur, J. (2014). A comprehensive review on metabolic syndrome. Cardiology Research and Practice, 2014(March). https://doi.org/10.1155/2014/943162

10. Laine, M. K., Eriksson, J. G., Kujala, U. M., Kaprio, J., Loo, B. M., Sundvall, J., Sarna, S. (2016). Former male elite athletes have better metabolic health in late life than their controls. Scandinavian Journal of Medicine and Science in Sports, 26(3), 284-290. https://doi.org/10.1111/sms. 12442

11. Panayiotoglou, A., Grammatikopoulou, M. G., Maraki, M. I., Chourdakis, M., Gkiouras, K., Theodoridis, X., Hassapidou, M. N. (2017). Metabolic syndrome in retired soccer players: A pilot study. Obesity Medicine, 8, 15-22. https://doi.org/10.1016/j.obmed.2017.09.004 
12. Saidunnisa, Begum, Shariff Atiqulla, and Ghufran Ayman. "Prevalence of Polycystic Ovarian Syndrome among Students of RAK Medical and Health Sciences University United Arab Emirates. "International Journal of Medicine and Pharmaceutical Science (IJMPS) 6.1, Feb 2016, 109-118

13. Singh, Jaspreet, and A K Pandey. "Clinical Evaluation of Puskarmula (Inula Racemosa) Capsule in the Patients of Metabolic Syndrom E." International Journal of Medicine and Pharmaceutical Sciences (IJMPS) 4.2 (2014): 9-20.

14. The U.S. Department of Health and Human Services. The National Heart, Lung, and B. I. T. E. C. (2004). The Seventh Report of the Joint National Committee on Prevention, Detection, Evaluation, and Treatment of High Blood Pressure.

15. World Health Organization. (n.d.). WHO guidelines on drawing blood : best practices in phlebotomy. 2010. 